\title{
3.7 Hypertension and Impaired Carbohydrate Tolerance
}

E. Colli (1), R. Pedrazzoli (1), S. Onolfo (1), E. Scaglia (1), G.P. Carnevale

Schianca (1), E. Bartoli (1)

(1)Università Piemonte Orientale, Ospedale Maggiore, Novara, Italy

Introduction. Patients suffering from hypertension and patients with type 2 diabetes exhibit a high cardiovascular risk. Moreover, hypertension alone doubles the risk of developing diabetes. In this study we examined impaired carbohydrates tolerance (ICT) in a group of subjects whose fasting plasma glucose (FPG) was less than $125 \mathrm{mg} / \mathrm{dl}$.

Methods. We recruited 721 subjects (aged 53.2 $\pm 12.7 ; 341$ male and 380 female) studied by OGTT and classified as normo-gluco-tolerant (NGT) if FPG $<100 \mathrm{mg} / \mathrm{dl}$ and 2 hours plasma glucose ( $2 \mathrm{~h}-\mathrm{PG}$ ) $<140 \mathrm{mg} / \mathrm{dl}$, as ICT if FPG $>100 \mathrm{mg} / \mathrm{dl}$ and/or $2 \mathrm{~h}-\mathrm{GP}>140 \mathrm{mg} / \mathrm{dl}$. These subjects were divided into four groups depending on the duration of hypertension: 1-5 years (group A), 6-10 years (group B), 11-15 years (group C), more than 15 years (group D).

Results. Group A includes 445 subjects, 58,4\% NGT and 41,6\% ITC. Group B includes 119 subjects, $52,1 \%$ NGT and $47,9 \%$ ICT. Group C includes 82 subjects, $40,2 \%$ were NGT and $59,8 \%$ ICT. Group D includes 75 subjects, 33,3\% NGT and 66,7\% ICT. The percentage of NGT subjects decreases gradually with the progressive prolongation of the duration of hypertension whilst the opposite trend is displayed by ICT, the percentage of which rises progressively $(\mathrm{X} 2=22.2, \mathrm{p}<0.0007)$. It is important to notice that a larger percentage of hypertensive patients $(41,6 \%)$ suffers from ICT at the beginning of their disease. Since the age of our population rises with the duration of hypertension, we performed the ANOVA analysis to estimate the importance of age: this variable does not influence the comparison between group $B$ and $C(p=0.52)$ and between $C$ and $D(p=0.17)$. Restricting our analysis to subjects aged $<60$ years, the age variable was more homogeneous than in the other groups. Even in this more limited population we confirm that the percentage of NGT shows an inverse relationship with duration of hypertension. The same was true in subjects aged more than 60 years affected by hypertension for more than 10 years.

Conclusions. Our data confirm the strong association between hypertension and impaired carbohydrates tolerance insomuch as ICT onset becomes progressively more likely with the length of hypertension. 